\title{
Rock, Bone, and Ruin: A Trace-centric Appreciation
}

\author{
Alison Wylie*
}

\begin{abstract}
Currie's expansive, practice-grounded account of how historical scientists "make their own [epistemic] luck" is a pivotal reset for philosophy of the historical sciences. I particularly welcome his arguments against the various forms of epistemic atomism that have inclined philosophers to an overstated pessimism about the epistemic status of fields whose subject domain is the past. Nonetheless I argue that there is more continuity between the evidenceconstituting strategies recognized by trace-centric theorists and the non-trace, "surrogative" streams of evidence to which Currie draws attention.
\end{abstract}

\section{Keywords \\ analogy $\bullet \operatorname{archaeology} \bullet$ evidence $\bullet$ models $\bullet$ simulation $\bullet$ traces}

Part of an author-meets-critics book symposium on Rock, Bone, and Ruin: An Optimist's Guide to the Historical Sciences (2018, MIT Press) by Adrian Currie, with Adrian Currie, Leonard Finkelman, Joyce C. Havstad, and Derek Turner.

I am on record as a fan of Rock, Bone, and Ruin, and I was pleased to discover that, in our paired cover blurbs, Martin Rudwick and I make essentially the same point: the great virtue of Rock, Bone, and Ruin is that Adrian Currie combines what you might describe as a jeweler's-eye view, in his attention to the messy details of research practice in the historical sciences, with a cartographer's breadth of vision that, as Rudwick puts it, leads him to "explore the surprising commonalities that underlie these superficially diverse sciences." Rather than appraising the epistemic prospects of the historical sciences against an abstract, trans-contextual template, Currie builds this breadth from close analysis of the strategies by which epistemically "unlucky" historical scientists parlay their limited evidential resources into a robust understanding of temporally remote geological events, evolutionary processes and cultural dynamics. As a demonstration of how productive such a turn to practice can be, Currie's approach has meta-philosophical implications to which I return at the end, but first I offer a selective review of his appraisal of the limitations of trace-centric accounts.

*Canada Research Chair and Professor of Philosophy, University of British Columbia, BUCH E370, 1866 Main Mall, Vancouver, BC V6T 1Z1, Canada, alison.wylie@ubc.ca

Received 27 March 2019; Accepted 2 April 2019 doi:10.3998/ptpbio.16039257.0011.008 


\section{Evidence Beyond Traces}

As an avowedly trace-centric philosopher of archaeology myself, I was initially taken aback by some aspects of the arguments Currie develops in the first third of Rock, Bone, and Ruin. There he argues that a preoccupation with the strengths and weaknesses of trace-based evidence obscures the rich diversity of the types of evidence deployed by historical scientists, particularly when this underwrites a presumption that they are inevitably at a disadvantage, compared to experimental scientists, because they cannot generate their own data; they cannot "make their own luck" $(2018,135)$, but must rather depend on the vagaries of trace generation and preservation to deliver them evidence of the pasts they investigate.

I share Currie's impatience with such views; historical scientists reason with a much wider range of evidential resources than is recognized in caricatures of their epistemic predicament constructed for philosophical purposes. That said, what's not to love about traces? Philosophically minded archaeologist Gavin Lucas (2015) documents the legacy of two distinct ways of construing the metaphors that attach to traces: as incomplete, degraded fragments on one hand but also, on the other hand, as hardy survivors, robust if recalcitrant witnesses to the past. Being dispositionally an epistemic optimist I had always found the latter view more congenial; I have been inclined to blame the periodic swing to pessimism among archaeologists on the baleful influence of untenably narrow philosophical conceptions of science rather than on the traces themselves (Wylie 2002). If pessimism is warranted, it is in a form that complements Currie's "local optimism"; it attaches to specific uses of evidence and research programs in the historical sciences, not to the entire enterprise $(2018,281)$. So I share Currie's reservations about the kind of trace-centrism that recognizes, as a source of historical evidence, only material survivors "downstream of the target" that can be directly connected to the target genealogically and causally. And I am as uncompelled as he is by expansive philosophical claims about the epistemic standing of the historical sciences that are based on an appraisal of this evidential resource, narrowly defined.

Nonetheless, I do find overstated the sharp distinction Currie draws between trace-based modes of evidential reasoning and the under-appreciated strategies of inquiry he is intent on bringing into focus that exploit "non-trace" evidence. Trace-centric analyses of the kind I have advocated, reflecting on archaeological practice, turn on expanding our conception of what "traces" are and how they function as evidence. Integral to these is a recognition that, in mobilizing traces as evidence, archaeologists rely upon a number of features of evidential reasoning that Currie associates with distinctively non-trace streams of evidence. I identify three points where I see continuity rather than a disjunction between trace-centric and non-trace methodologies in the historical sciences.

The first is an appreciation that the action in evidential reasoning with traces is mostly offstage: what makes it possible to identify traces as archaeological and interpret them as evidence is a vast array of technical skills and background knowledge that archaeologists build themselves or import from fields as diverse as physical chemistry and botany, ethnography and sociology, neuroscience and physiology (Wylie 2011, 389). This is a crucial sense in which, as Currie argues, "epistemic atomism" is a non-starter $(2018,74)$. Even the most uncompromising archaeological empiricists insist on the central role of "middle-range theory"-in the sense of conceptual and empirical "gap-crossers" - in mediating the identification and interpretation of traces as evidence (Raab and Goodyear 1984; Kosso 1993). The virtue of Toulmin-schemas (Toulmin 1958), in terms of which Bob Chapman and I (Chapman and Wylie 2016, 35-39) have characterized the complex evidential arguments-in-use, is that they emphasize the centrality of "warrants" for evidential claims, where warrants are construed, not as formal inference 
rules, but as substantive background knowledge that underwrites what Norton (2003) characterizes as material induction. On a trace-centric understanding, as Currie characterizes it, the goal of the historical scientist is to reconstruct the antecedents that, on knowledge of present systems and processes, could or most likely did produce these traces, but he sees these inferences as limited by a preoccupation with dependencies between past events or conditions and the material traces that survive of them in the present; what "midrange theories allow us to exploit" are (just) dependencies between past and present. What's missing, he argues, is a consideration of the ways in which historical scientists make their own epistemic luck by "exploiting dependencies between past events" (61), or between the entities (135), variables (74) or aspects (11) of a target past that comprise an historical subject. This is a matter of shifting the focus of philosophical attention to practices that use background knowledge to reconstruct what I will refer to as past:past, rather than past:present, dependencies.

In archaeological contexts and, from the examples Currie discusses, in other historical sciences, there are very few cases in which a middle-range theory or mediating warrant has sufficient specificity and security to carry an argument for interpreting a surviving trace as evidence of a specific antecedent without drawing on a network of inferences that take into account past:past as well as past:present dependencies. Reconstructing the reduction sequence for obsidian tools might be one such case. The properties of volcanic glass are such that at least some of the linking principles involved are bi-conditional: there may be just one way that a particular form of tool could have been produced. Typically, however, the determination that a given element of middle-range theory applies to a particular trace, and adjudications of the plausibility of the past:present dependencies posited on this basis, depends on a consideration of exactly the past:past dependencies that interest Currie. Radiocarbon dating may seem to exemplify tracecentric reasoning of a high order, where linking principles from physical chemistry establish a direct and incontrovertible causal connection between the past event of sample death and the composition of a surviving trace, specifically, the ratio of radioactive to (decayed) stable carbon. In practice, however, a great deal of collateral knowledge about the conditions under which the organic sample was originally formed - the past:past dependencies between its mode of carbon uptake and its environment, for example - as well as a series of subsequent past:past dependencies that comprise its depositional and post-depositional history-must be considered even to estimate the date of sample death let alone interpret this as evidence relevant for constructing archaeological chronologies (Wylie 2019).

This suggests that, except in a few rare cases, epistemic atomism is untenable in a second sense. Even the most straightforward of past-present trace-centric reasoning proceeds by means of cables, rather than chains of inference (Wylie 2002, chap. 11), and the strands that make up the cables typically include inferences about past:past dependencies that inform discerning judgements about how a particular trace (or aspect of a trace) can plausibly be linked to a particular event, set of conditions or aspect of the target past. This seems exactly in line with Currie's account of how historical scientists "make their own luck" but, I would argue, it is a ubiquitous feature of the types of evidential reasoning privileged by trace-centric theorists that he contrasts with the streams of non-trace evidence central to his own theory-dependent" account of evidential reasoning in the historical sciences $(2018,73,122)$.

The role of off-stage resources is especially clear in the case of analogical inference, which Currie cites as a primary example of "surrogative" evidence. This is a second area where I find the distinctions between trace and non-trace evidence overdrawn. In archaeological contexts analogical reasoning has been particularly contentious on grounds that it is an ampliative form of inference that is especially vulnerable to the projection of presentist, ethnocentric assumptions onto the past. At various points the case has been made that, if archaeologists are not 
to "paint themselves into a corner"-that is, reconstruct the cultural past in the image of, or as required by, some present-they should eschew reliance on analogy altogether (Wylie 1982; 2002, 144-147). Thinking this through in trace-centric terms I have argued that the empirical and conceptual "source-side" work archaeologists do in mobilizing analogies is crucial to their credibility and in this connection I made two points that resonate with Currie's account. The first is that compelling analogical inference depends on delineating what Julian Weitzenfeld described in the early 1980s as "determining structures": dependencies between properties of the source and the target of an analogy that, despite his terminology, need not be deterministic (1982). This captures, in the context of analogical reasoning, the dependence relations central to middle-range theory that Currie (2018, 73-80) usefully characterizes as ranging from minimal, fragile and local to maximally deterministic and entrenched. Building on this point I made a case for developing what Rom Harré had described as "multiply connected" analogies; this seemed an apt framework for characterizing the archaeological practice of stitching together elements of a number of partial analogues to characterize a target that is unlike any single current analogue (Wylie 2002, 153; Harré 1970, 47-49). Currie's (2018, 203-228) “exquisite corpse strategy" captures exactly this strategy of working with analogies. And, like Currie, I saw it as a source of evidential support, by contrast to the view he finds articulated in particularly stark terms by Holly Hayter (1994): that analogical reasoning is never more than a heuristic; it is strictly non-evidential and should be confined to the context of discovery. In addition to the coherence testing that Currie emphasizes in connection with multiply-connected analogues, systematic empirical analysis of the conditions under which a particular dependency holds in source contexts can disconfirm as well as provide support for interpretive, reconstructive and explanatory claims based on analogical inference. In both cases analogies carry evidential weight.

That said, I am not convinced that analogical reasoning, so conceived, is in all cases a source of non-trace evidence. Much depends on what use historical scientists make of analogy and, in archaeological contexts, it is mobilized for a number of different purposes. In some cases analogies are used to reconstruct quite specific antecedent events or conditions that generated surviving traces, for example, in attributions of function, or in inferring production technologies or patterns of use that could have produced the traces in question. These do seem reasonably characterized as trace-centric uses of analogy, with the caveat (as above) that even the reconstruction of specific past:present dependencies typically depends on inferences about past-past dependencies. In other cases, however, analogies inform the construction of broader-scale models whose targets range from components of a past cultural system-subsistence or technological practices, social relations, cultural lifeworlds- to "whole system" models (Kohler and van der Leeuw 2007; Wylie 2017). And in these cases it does seem plausible that analogical inference supports modelling practices that can put historical scientists in a position to generate non-trace evidence of the kind that particularly interests Currie. In this connection, I especially welcome Currie's sustained engagement with modelling practices in the historical sciences where the performance data generated by experimental interventions on "the world in the model" (Morgan 2012) do constitute a source of non-trace evidence that can significantly reframe, extend, and disconfirm as well as confirm models that posit the specifics of how actually, as well as how possibly, the dynamics of a particular past operated or set of events unfolded (Wylie 2017: 997999). Indeed, I would argue that Currie could build a stronger case for the distinctive nature of model-generated evidence drawing on the kinds of arguments Morrison makes in Reconstructing Reality (2015) for recognizing that models are implicated in the construction and interpretation of experiments all the way down; there is more continuity between experiments on real-world specimens and models than typically recognized. 
A third point generalizes my earlier observation about the cables of inference required to reason with traces that is congenial to Currie's account but, I believe, also militates against a sharp distinction between trace and non-trace modes of evidential reasoning in the historical sciences. It is that the technical, empirical, and conceptual/theoretical resources required to constitute traces as evidence get a good deal more epistemic traction when they function as an interlocking "tangle" of evidence than any one line of evidence can on its own (to use a metaphor of Norton's $[2014,673])$. Various forms of robustness reasoning are a standard strategy by which archaeologists exploit the networks of mutual constraint and reinforcement that operate between distinct lines of evidence when these bear on "the same" target. An important point Currie makes in this connection is that not all uses of multiple lines of evidence are instances of consilience. When multiple sources are used analogically to construct an "exquisite corpse," they bear on different aspects of the target so these lines of evidential reasoning cannot be said to converge on exactly the same target. This is why, Currie argues, we should understand analogues to be a strategy for generating a non-trace stream of evidence, not just interpretive scaffolding that mediates the use of traces as evidence. And it is one reason why, on my account, trace-based reasoning routinely depends upon inferences about past:past as well as past:present dependencies. Even so, as Currie acknowledges, the strategies of coherence testing and simulation that he sees as a primary source of non-trace evidence are only viable given an assumption that the components of a multiply-connected analogue are interrelated elements of a past event or state of affairs. Indeed, establishing that they are is a hard-won empirical, conceptual achievement that is crucial for trace-based reasoning as well. So it would seem that robustness reasoning is involved after all even if, I agree, it should not be elevated to the status of being "the" defining method of the historical sciences (Currie 2018, chap. 8).

In short, some of us trace-centric theorists drew similar lessons from the analysis of actual practices of evidential reasoning in the historical sciences as figure centrally in Currie's account: that in the absence of "infallible foundations" (Chang 2004, 231) historical scientists are methodological omnivores who rely on many different strategies to build mutually constraining and stabilizing tangles of evidence. In countering implausibly narrow conceptions of traces and the strategies of inference by which they are leveraged as evidence, the central lesson from practice is that historical scientists almost never rely on silver bullet inferences from a singular trace to specific target-of-interest antecedents. Epistemic atomism is untenable in at least three senses-with respect to traces themselves, the warrants required to interpret them as evidence, and the uses of evidence so constituted to build an understanding of past entities and events, processes and conditions of life. In this the historical sciences are not so different from any number of other scientific fields whose epistemic status has never been impugned on grounds that their subject domain is the past. Certainly it would seem that attention to practice should lead trace and non-trace theorists alike to Currie's conclusion that there are no grounds for non-local epistemic pessimism about the historical sciences.

\section{Methodological Omnivory for Philosophers}

Despite resisting the sharp distinctions Currie draws between trace and non-trace accounts of evidential reasoning, I see Rock, Bone, and Ruin as a pivotal reset for philosophy of the historical sciences, and I count its meta-philosophical implications as among its most significant contributions. As I noted at the outset, Currie demonstrates what is to be gained by combining close analysis of strategies-in-use with an expansive comparison of modes of evidential reasoning across the historical sciences. In my case, a thoroughgoing practice turn-an immersion in analysis of internal debates and strategies of inquiry specific to archaeology-reinforced an 
impulse to ignore what seemed to me, at the time, sterile scholastic debates among philosophers about the inherent limitations of the historical sciences. Currie not only broadens the horizons of our thinking about the historical sciences in a richly practice-grounded way, he also works through the details of a sophisticated new generation of philosophical arguments between epistemic optimists and pessimists. His "ripple model" of trace-based evidence is an enormously productive reframing of what is at stake philosophically in debate about the epistemic standing of the historical sciences. In this connection he makes a compelling case for preferring nuanced, case-by-case assessments of the epistemic credibility of particular research strategies as a mode of practice that promises to move us decisively beyond a familiar philosophical stalemate.

To build these arguments, Currie is himself, of necessity, a content omnivore, deeply immersed in an impressive range of philosophical and scientific literatures. Not surprisingly, what he learns about the historical sciences pushes the traditional limits of philosophical analysis. However, if we are to adjudicate the prospects for epistemic success at the level of specific research programs and types of practice, as he recommends, we need a different kind of omnivory. We need to mobilize the resources of our best empirical studies of science. Questions about whether a given line of historical inquiry is likely to realize the direct and indirect epistemic goods described by Currie in the final chapter of Rock, Bone, and Ruin depends on understanding not just the funding policies he considers, but also the institutional structures, disciplinary cultures, path-dependent social dynamics, and trading zones that configure and are configured by these policies, all of which are crucial scaffolding for building virtuous tangles of evidence in the historical sciences. The implication is that, if we are to realize the promise of the philosophical research program Currie advocates, we must cultivate practices of methodological omnivory in philosophy, much as historical scientists do. In the spirit of Currie's $(2018,275)$ self-declared non-conclusion - that he is more interested in "motivating further research than [having] the last word"-I take Rock, Bone, and Ruin to be an invitation to think together about how we might best do this: What kinds of training, funding, and institutional configurations do we need to address jointly normative and empirical questions about the conditions for epistemic success, in the historical sciences and elsewhere?

\section{Literature cited}

Chang, Hasok. 2004. Inventing Temperature: Measurement and Scientific Progress. Oxford: Oxford University Press.

Chapman, Robert, and Alison Wylie. 2016. Evidential Reasoning in Archaeology: Bloomsbury.

Currie, Adrian. 2018. Rock, and Ruin: An Optimist's Guide to the Historical Sciences. Cambridge, MA: MIT Press.

Harré, Rom. 1970. The Principles of Scientific Thinking. Chicago: University of Chicago Press.

Hayter, Hollie. 1994. "Hunter-gatherers and the Ethnographic Analogy: Theoretical Perspectives." Totem: University of Western Ontario Journal of Anthropology 1 (1): 39-49.

Kohler, Timothy A., and Sander E. van der Leeuw, eds. 2007. The Model-Based Archaeology of Socionatural Systems. Santa Fe, NM: SAR Press.

Kosso, Peter. 1993. "Middle-Range Theory in Historical Archaeology." Studies in History and Philosophy of Science 24: 163-184.

Lucas, Gavin. 2015. "Evidence of What? On the Possibilities of Archaeological Interpretation.” In Material Evidence: Learning From Archaeological Practice, edited by Robert Chapman and Alison Wylie, 311-323. London: Routledge.

๑ OPEN ACCESS - PTPBIO.ORG 
Morgan, Mary S. 2012. The World in the Model. Cambridge Cambridge University Press.

Norton, John D. 2003. “A Material Theory of Induction.” Philosophy of Science 70 (4): 647-670.

Norton, John D. 2014. “A Material Dissolution of the Problem of Induction.” Synthese 191: 671-690.

Raab, L. M., and A. C. Goodyear. 1984. "Middle-Range Theory in Archaeology: A Critical Review of Origins and Applications." American Antiquity 49 (2): 255-268.

Toulmin, Stephen E. 1958. The Uses of Argument. Cambridge: Cambridge University Press.

Weitzenfeld, Julian S. 1983. "Valid Reasoning by Analogy." Philosphy of Science 51: 137-149.

Wylie, Alison. 1982. “An Analogy by Any Other Name is Just as Analogical.” Journal of Anthropological Archaeology 1: 382-401.

Wylie, Alison. 2002. Thinking from Things: Essays in the Philosophy of Archaeology. Berkeley, California: University of California Press.

Wylie, Alison. 2011. "Critical Distance: Stabilising Evidential Claims in Archaeology." In Evidence, Inference and Enquiry, edited by Philip Dawid, William Twining and Mimi Vasiliaki, 371-394. London: Oxford University Press.

Wylie, Alison. 2017. "Representational and Experimental Modeling in Archaeology." In Springer Handbook of Model-Based Science, edited by Lorenzo Magnani and Tommaso Bertolotti, 989-1002. Amsterdam: Springer.

Wylie, Alison. 2019. “Temporal Data That Travel: Radiocarbon Dating and Robustness Reasoning in Archaeology." Prepared for Varieties of Data Journeys, edited by Sabina Leonelli and Niccolò Tempini.

(C) 2019 Author(s)

This is an open-access article distributed under the terms of the Creative Commons Attribution 4.0 International license, which permits anyone to download, copy, distribute, display, or adapt the text without asking for permission, provided that the creator(s) are given full credit.

ISSN 2475-3025 